\title{
Laboreal
}

Volume $15 \mathrm{~N}^{\circ} 1$ | 2019

Trabalho e cooperação

\section{Jean-Charles Lebahar: a construção de uma investigação singular e exigente para formar em conceção e compreendê-la}

Jean-Charles Lebahar: la construcción de una investigación singular y exigente para comprender y formar al diseño

Jean-Charles Lebahar: la construction d'une recherche singulière et exigeante, pour comprendre et former à la conception

Janine Rogalski

Tradutor. João Viana Jorge

\section{(2) OpenEdition}

Journals

Edição electrónica

URL: http://journals.openedition.org/laboreal/1636

DOI: $10.4000 /$ laboreal.1636

ISSN: 1646-5237

Editora

Universidade do Porto

Refêrencia eletrónica

Janine Rogalski, « Jean-Charles Lebahar: a construção de uma investigação singular e exigente para formar em conceção e compreendê-la », Laboreal [Online], Volume $15 N^{0} 1$ | 2019, posto online no dia 01 julho 2019, consultado o 24 setembro 2020. URL : http://journals.openedition.org/laboreal/1636 ; DOI : https://doi.org/10.4000/laboreal.1636

Este documento foi criado de forma automática no dia 24 setembro 2020.

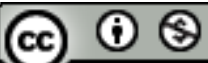

Laboreal está licenciado com uma Licença Creative Commons - Atribuição-NãoComercial 4.0 Internacional. 


\section{Jean-Charles Lebahar: a construção de uma investigação singular e exigente para formar em conceção e compreendê-la}

Jean-Charles Lebahar: la construcción de una investigación singular y exigente para comprender y formar al diseño

Jean-Charles Lebahar: la construction d'une recherche singulière et exigeante, pour comprendre et former à la conception

Janine Rogalski

Tradução : João Viana Jorge

\section{REFERÊNCIA}

Comentario ao texto: Lebahar, J.-Ch. (2007). La conception en design industriel et en architecture. Désir, pertinence, coopération et cognition (pp. 15-21). Paris: Hermes-

Lavoisier.

Manuscrito recebido em: dezembro/2017

Aceite após peritagem: outubro/2018

2 A introdução de «La conception en design industriel et en architecture. Design, pertinence, coopération et cognition " apresenta uma síntese de um longo trabalho de modelização visando ter em conta a integridade da atividade de conceção. J.-C. Lebahar foi um precursor desta abordagem na qual ocupa uma posição singular e na qual desenvolveu o estudo com grande exigência teórica e metodológica. Foi isso que o levou a questionar um muito extenso campo de abordagens e a desenvolver uma "complementaridade" num movimento que nos limitaremos a esboçar aqui, seguindo a cronologia das suas publicações. 


\section{O desenho como instrumento cognitivo de simulação}

3 A obra princeps de 1983, "Le dessin d'architecture: simulation graphique et réduction d'incertitude ", primeiro balanço de pesquisas sobre arquitetos reconhecidos ou em formação é a mais frequentemente citada. Lebahar põe aí em evidência o papel central do desenho como instrumento cognitivo (ainda que este termo "vygotskiano" não seja utilizado) [1]. Uma primeira originalidade de Lebahar foi então a de sublinhar a importância da função de "simulação" que permite uma representação mental ou um desenho e o papel determinante que este desempenha na gestão da "incerteza epistémica" característica das tarefas complexas de conceção. A epistemologia piagetiana vai constituir uma referência essencial das análises teóricas de Lebahar em duas direções: a epistemologia do espaço e a dialética assimilação/acomodação. Por um lado apoia-se em Piaget e Inhelder (1972) para abordar a multiplicidade dos «espaços» manipulados pelo arquiteto: espaço quantitativo das medidas euclidianas, espaços qualitativos da topologia e de dimensões técnicas dos equipamentos, espaço construtivo relevando da tecnologia para tratar dos constrangimentos de solidez, bem como os espaços operativos que intervêm através da prática gráfica e para a análise dos quais fará apelo à semiologia com referência a Ducrot (1967) e Prieto (1966). Por outro lado, tratando-se de ferramentas de conceção, Lebahar insiste na necessidade de trabalhar com sistemas que permitam a reversibilidade das operações mentais e a utilização do grafismo como simulação «aproximativa». Esta problemática da reversibilidade (concepção muito piagetiana) aparece desenvolvida no artigo do Travail Humain: «Le travail de conception en architecture : contraintes et perspectives apportées par la CAO» (1986), em que a deformabilidade e a reversibilidade das operações aparecem notoriamente sublinhadas. Lebahar integra aí pontos de vista oriundos em simultâneo da psicologia ergonómica, em referência a Ochanine $(1966,1978)$ e do quadro piagetiano. Por um lado, cada simulação constitui «uma imagem operativa reversível» (p. 20) e, por outro, existe uma dinâmica de articulação aquisição/progressão no decurso do desenho que desempenha um papel de exploração proactiva (p. 28). Nele, Lebahar considera o desenho como um «sinal operatório» no sentido em que os seus traços assinalam imagens operativas interiorizadas. De facto, ainda que nada disso tenha sido dito na altura [2], a utilização do quadro da cognição como tratamento da informação aparece mais como metodológica que teórica.

\section{Planificação e regulação na atividade de conceção}

4 Um novo artigo é consagrado a «alguns pontos de planificação significativa da atividade de conceção em design industrial» (Lebahar, 1992). Pode aí ler-se uma integração de problemáticas então desenvolvidas em psicologia ergonómica. A planificação aparece como «forma de organização funcional da sua própria atividade cognitiva», implicando para quem concebe uma hierarquia de estratégias com diversos níveis de representação da tarefa e da sua atividade. J.-C Lebahar situa-se numa abordagem dos mecanismos de regulação da atividade de conceção: planificação, representações sequenciais de problemas particulares, «simulação» a partir de hipóteses relativas a certos aspetos visualizáveis do objecto, que são reversíveis e transformáveis (reencontra-se Piaget) e que permitem controlar as etapas dos estados do objeto "conteúdo" da atividade de 
conceção [3]. O ter em conta a planificação como "esquema operativo" (p. 331) adiciona uma dimensão suplementar ao quadro de inspiração piagetiana e conduz a questionarlhe a suficiência.

Num artigo ulterior na mesma revista (Lebahar, 1996) aparecem referências à ergonomia cognitiva: Richard (1990) é citado sobre a ligação entre a atividade de resolução de problemas e as representações, e Falzon (1995) sobre o raciocínio da conceção.

6 Lebahar desenvolve aí a ideia que o desenhador CAO se encontra em interação com três sistemas: o grupo de especialistas (objeto a conceber), o sistema CAO, e as representações (como modelos de simulação), tripla interação que opera em ciclos de simulação.

\section{O designer no cerne de um sistema de interações}

70 artigo que se seguirá «Complexité des compétences de création industrielle: Qui évalue ? Quoi ? Comment ?» (1997), introduziu uma nova temática, a «clarificação do conceito de competências» para «daí retirar a ambiguidade fundamental» (p. 151). Lebahar vai aqui separar-se explicitamente da análise cognitiva desenvolvida até agora porque «uma abordagem meramente cognitiva não é suficiente para explicar a competência» na medida em que «a potencialidade cognitiva e os esquemas instrumentais [são] extraídos de uma interação com um dado meio sociotécnico» (p. 155). O modelo apresentado a seguir situa o sujeito-designer no cerne de um complexo de interações no qual se articulam as organizações sociais e técnicas do trabalho de conceção, os outros atores, os conhecimentos próprios de quem concebe, os instrumentos de simulação e de comunicação que permitem produzir a simulação. Este modelo, proposto por Lebahar, é mais inovador do que outras modelizações que se inscreverão num movimento baseado no caráter situado da atividade de conceção [4].

O retorno explícito à temática da formação mostra a permanência da referência teórica piagetiana. Num estudo comparativo de duas abordagens didáticas do ensino de projeto em arquitetura (2001), Lebahar insiste na importância da dialética entre os dois processos avançados por Piaget: a assimilação - na qual se desenrola o imaginário, a autonomia de controlo das escolhas e o seu caráter pessoal - e a acomodação - que pressupõe a tomada de consciência das relações entre desejos e constrangimentos e uma autocrítica constante.

9 A elaboração continuada do modelo «sujeito que concebe» prossegue no documento de síntese apresentado para a Habilitação para Dirigir Investigações (Habilitation à Diriger des Recherches) (2003). Releva-se particularmente o enriquecimento - e a complexidade - da análise do artefacto (em vista na conceção), entidade material e cognitiva enquanto objeto e enquanto sistema. Cada um destes dois pontos de vista (objeto e sistema) é declinado segundo uma hierarquia de dimensões. No que concerne ao objeto: posição, substância, entidade espacial, elemento de uma rede semântica para o objeto. Do ponto de vista do sistema, Lebahar distingue uma dinâmica externa, considerada de acordo com os dois meios: material e humano, e uma dinâmica interna, com diversas dimensões: mecânica, funções internas, energia, autonomia, etc., implicando numerosos domínios de conhecimento. A análise da tarefa sublinha-lhe as dimensões teleológica, axiológica e técnica (de onde releva a semiologia). Lebahar explicita então 
(finalmente!) que o modelo de tratamento da informação é um «esquema fenómeno/ gráfico», quer dizer uma metodologia de descrição.

\section{A complementaridade entre abordagens disciplinares}

10 A complementaridade entre abordagens disciplinares [5] enriqueceu-se ao longo do trabalho de J.-C. Lebahar, com uma articulação cada vez mais estreita a nosso ver: qualificaremos de bom grado a sua complementaridade como integradora [6]. Chamaríamos de boa vontade «multiplicidade», no sentido de um espaço metodológico multidimensional, a esta complementaridade entre abordagens disciplinares. Segue a par das colaborações críticas que J.-C. Lebahar mantém com outros especialistas da investigação pública assim como com atores concretos da conceção (técnicos, engenheiros, profissionais da concepção) e professores e estudantes de design e de arquitetura.

11 Poderia dizer-se que há, nestas interações, dimensões simultaneamente «centrífugas» e «centrípetas» face ao sujeito. As organizações sociais e técnicas do trabalho de conceção, os outros atores do processo global de conceção, os instrumentos de simulação e de comunicação, a própria tarefa de conceção e de comunicação de um modelo de artefacto respondendo aos constrangimentos do caderno de encargos e da técnica, vêm «do exterior» do sujeito; a atividade de conceção e as competências vêm «do interior».

12 A noção de desdobramento cognitivo que propõe Lebahar para analisar a atividade do sujeito que concebe permite uma abordagem que nos parece mais rica do que a coberta pela noção e a prática da reflexividade; integra componentes da abordagem «situada» da conceção (o lugar das organizações e dos outros atores) bem como conceitos de psicologia cognitiva. Acrescem considerações de ordem semiológica como o facto de as produções gráficas, "externalizando" operações mentais, abrirem a possibilidade do discurso consigo próprio como com outrem.

13 Quando Lebahar sublinha que o jogo entre "assimilação subjetiva" e "assimilação operativa" pode exprimir a competência de um designer perito, pode perguntar-se se isso não seria uma forma elaborada de criatividade? A questão não é colocada por Lebahar que pouco ou nada utilizou esse termo no decurso do seu trabalho de investigador, mas não nos parece interessante tomar sob esse ângulo a problemática da criatividade - uma das originalidades teóricas que podem relevar-se na obra de síntese de 2007 (encontrar-se-á uma análise detalhada em Leplat, 2008). Poder-se-ia também agregar a essa temática a apresentação feita (p. 268) do "exercício de redução» que «consiste em estabelecer uma espécie de cartão de identidade do produto por meio de um aforismo, de um texto poético ou de uma representação sintética» que «permite [ao estudante] reduzir, hierarquizar e memorizar um esquema concetual durante toda a conceção»; poderíamos acrescentar que isso poderia também contribuir para o jogo entre as duas vertentes da assimilação.

\section{0 investigador (visto) como o que concebe ...}

14 Lebahar abordou a questão dos elementos comuns à análise da atividade do sujeito que concebe, tal com ele a construiu e à do sujeito investigador: «se essa apresentação [...] 
tende a aproximar a atividade do observador/analista da de um sujeito que concebe. [...] a comparação é, todavia, limitada. O valor de um objeto físico em três dimensões concebido por um especialista para satisfazer um objeto social bem definido [...] pode verificar-se imediatamente e com precisão desde a colocação em serviço. Não é o caso de um modelo da atividade de quem concebe fornecido por um investigador com os seus trabalhos».

Parece-me que esta (auto)avaliação é injustamente crítica. Primeiro porque o modelo que elaborou para quem concebe pode também ser desenvolvido para outros tipos de conceção materializados de maneira bem mais indireta como é, por exemplo o caso da conceção de programas informáticos. Por outro lado, porque as virtudes do uso da investigação não podem ser julgadas a curto prazo nem pela existência de utilizações que deixem o quadro teórico intocado: na investigação - mais que noutras áreas? - a conceção prossegue na utilização e não se pode senão desejar que a conceção teórica desenvolvida por Lebahar conheça múltiplos desenvolvimentos.

\section{BIBLIOGRAFIA}

Devereux, G. (1972/1985). Ethnopsychanalyse complémentariste. Paris : Flammarion.

Ducrot, O. (1967). Chronique linguistique. L'Homme, 7(2), 109-122.

Falzon, P. (1995). Les activités de conception : réflexions introductives. Performances Humaines \&

Techniques, 74, 6-11.

Goel, V., \& Pirolli, P. (1992). The structure of design problem spaces. Cognitive Science, 16, 395-429.

Hayes-Roth B., \& Hayes-Roth, F. (1979). A cognitive model of planning. Cognitive Science, 3, 275-310.

Lebahar, J.-C. (1983). Le dessin d'architecture : simulation graphique et réduction d'incertitude. Marseille : Editions Parenthèses.

Lebahar, J.-C. (1986). Le travail de conception en architecture : contraintes et perspectives apportées par la CAO. Le Travail Humain, 49, 17-30.

Lebahar, J.-C. (1987). Les dimensions cognitives du travail de conception en architecture avec utilisation de la CAO : compétences paradoxales révélées par les nouvelles pratiques graphiques. Dans R. Patesson (coord.), L'homme et l'écran. Aspects de l'ergonomie en informatiques (pp. 233-244). Bruxelles : Editions de l'Université de Bruxelles.

Lebahar, J.-C. (1992). Quelques formes de la planification significatives de l'activité de conception en design industriel. Le Travail Humain, 55, 329-351.

Lebahar, J.-C. (1996). L'activité de simulation d'un dessinateur de CAO dans une tâche de conception. Le Travail Humain, 59, 253-275.

Lebahar, J.-C. (1997). Complexité des compétences de création industrielle : qui évalue ? Quoi ? Comment? Connexions, 70, 151-164. 
Lebahar, J.-C. (1998). La simulation comme instrument de représentation et de régulation dans la conception de produit. Dans A. Weil-Fassina et P. Béguin (coord.), La simulation en ergonomie : connaître, agir et interagir (pp. 77-96). Toulouse : Octarès.

Lebahar, J.-C. (2001). Approche didactique de l'enseignement du projet en architecture. Didaskalia, 19, 39-77.

Lebahar, J.-C. (2005). L'activité cognitive du sujet concepteur. Communication présentée au Colloque national organisé par le Ministère de l'Education Nationale, l'Enseignement Supérieur et la Recherche : « Le design en question(s)», Paris, Novembre.

Lebahar, J.-C. (2007). La conception en design industriel et en architecture. Désir, pertinence, coopération et cognition. Paris : Hermès-Lavoisier.

Lebahar, J.-C. (2009). L'analyse de l'activité de conception : situations professionnelles, situations didactiques, perspectives. Skolê, 15, 53-74.

Leplat, J. (2008). Revue de l'ouvrage de Jean-Charles Lebahar « La conception en design industriel et en architecture. Désir, pertinence, coopération et cognition ». Pistes, 10(2).

Ochanine, D.A. (1966). The operative image of a controlled object in Man-automatic machine system. Congrès international de psychologie (pp. 48-57). Moscou, Symposium 27.

Ochanine, D. (1978). Le rôle des images opératives dans la régulation des activités de travail. Psychologie et Éducation, 2, 63-72.

Piaget, J., \& Inhelder, B. (1972). La représentation de l'espace chez l'enfant. Paris : PUF.

Prieto, L. (1966). Messages et signaux. Paris : PUF.

Richard J.-F. (1990). Les activités mentales. (Nouvelle édition revue et augmentée : « Les activités mentales. De l'interprétation de l'information à l'action », 2004). Paris: Armand Colin.

Visser W. (2009). La conception : de la résolution de problèmes à la construction de représentations. Le Travail Humain, 72, 61-78.

\section{NOTAS}

1. Um primeiro «período» bastante curto, logo após a publicação da obra inicial de 1983 ( $L$ Le dessin en architecture: simulation graphique et réduction d'incertitude») responde aos problemas que coloca a introdução da CAO nos ambientes da conceção em arquitetura pelo alargamento da temática ao design industrial e pela centração na atividade cognitiva e nas competências do sujeito que concebe.

2. Uma análise aprofundada da modelização da atividade cognitiva de Hayes-Roth \& Hayes-Roth (1979) conduzi-lo-á algures à conclusão que esse modelo não é adequado ao seu propósito.

3. Em divergência de Goel e Pirolli (1992), que visam então um modelo geral da conceção, como um tipo particular de resolução de problemas, Lebahar não toma como adquirida a invariância da atividade de quem concebe: apoiar-se-á nos dados dos estudos nos dois terrenos, da arquitetura e do design industrial, para identificar os invariantes e precisar onde se situam as diferenças.

4. Enriquece a análise para além do quadro «cognitive design research» tal como apresentado na revisão de literatura feita por Visser (2009). 
5. A integração de abordagens para modelizar a atividade de quem concebe parece-nos uma das características do quadro de análise de Lebahar: não a reencontramos nos diferentes modelos que puderam então ser elaborados.

6. Podemo-nos interrogar sobre se a noção de complementaridade é diferente da considerada por G. Devereux (que ele não cita, que eu saiba) como necessária no campo da etnopsiquiatria, entre - para ser breve - abordagem psicológica (psicanálise) do indivíduo e abordagem sociológica da sua conduta (antropológica). Devereux acentua de facto que a complementaridade não exclui nenhum modelo, nenhuma teoria válida: coordena-as (Devereux, 1972/1985, p. 27).

\section{AUTORES}

\section{JANINE ROGALSKI}

Groupe de Recherche et d'Etude sur l'Histoire du Travail et de L'Orientation (GRESHTO)

Centre de Recherche sur le Travail et le Développement (CRTD)

Conservatoire National des Arts et Métiers (CNAM)

41, Rue Gay Lussac 75005 Paris

France

rogalski.muret@gmail.com 